Research Paper

\title{
Treatment, Outcome and Prognostic Factors in Renal Cell Carcinoma - A Single Center Study (2000-2010)
}

\author{
Christof Achermann; Frank Stenner; Sacha I. Rothschild ${ }^{凶}$ \\ Department of Internal Medicine, Clinic of Medical Oncology, University Hospital Basel, Switzerland. \\ $\triangle$ Corresponding author: Sacha Rothschild, MD PhD. University Hospital Basel, Petersgraben 4, 4031 Basel, Switzerland. sacha.rothschild@usb.ch.
}

(C) Ivyspring International Publisher. Reproduction is permitted for personal, noncommercial use, provided that the article is in whole, unmodified, and properly cited. See http://ivyspring.com/terms for terms and conditions.

Received: 2016.02.08; Accepted: 2016.03.22; Published: 2016.05.08

\begin{abstract}
In Switzerland efficient availability of novel drugs for renal cell cancer (RCC) has been granted early. Since the advent of the targeted agents for RCC the usage of these drugs has been reported to improve progression free survival. Here, we find that patients who are able to receive sequential targeted therapy, including tyrosine kinase inhibitors (TKI) and mTOR inhibitors (mTORi), have a largely better outcome than those who have less exposure to these agents. The value of the prognostic scores developed by Motzer and Heng is fully reflected by the outcomes according to prognostic risk groups in our unselected patient cohort. Also, the use of surgical intervention appears to be an important prognostic factor, however with a somehow diminished effect by novel systemic therapies. The importance of multiple lines of targeted therapies is underlined by this retrospective analysis. For patients with metastatic RCC not receiving targeted therapy the median OS was 22.6 months compared to those with one TKI 25.4 months. Patients receiving a second-line therapy (median overall survival 27.6 months) and those patients with three or more lines of therapy (43.8 months) have the greatest benefit. Also, exposure to a mTORi improves survival versus non-exposure to mTORi (63.3 vs. 22.3 months, $p=0.038$ ). In conclusion a trend towards improved survival is confirmed for an unselected population when the full variety of therapeutic options is available and can be used for the individual patient.
\end{abstract}

Key words: Renal cell carcinoma, tyrosine kinase inhibitor, mTor inhibitor, metastasectomy, outcome, prognosis.

\section{Introduction}

Renal cell carcinoma (RCC) accounts for $2-3 \%$ of all adult malignancies, and about $90 \%$ of malignant renal tumors [1]. Risk factors include lifestyle variables such as active or passive cigarette smoking, obesity and hypertension [2]. There is also a correlation between RCC and end-stage renal failure as well as acquired renal cystic disease. Several autosomal dominant syndromes such as Von Hippel Lindau disease and tuberous sclerosis are known to have an association with RCC [3]. Clear cell RCC is the most common subtype accounting for $70-85 \%$ of cases [4].

Diagnosis of RCC is traditionally done by sonography, CT and MRI. Due to the widespread use of abdominal imaging for different indications, incidental diagnosis of small and asymptomatic RCCs has significantly increased in the past years. Surgical resection is the only curative therapeutic option in early tumor stages and patients with a limited number of metastasis [5-7]. Approximately one third of patients will eventually experience disease relapse as either local recurrence or distant metastasis, after initial surgical therapy $[8,9]$.

Introduction of novel targeted therapies has substantially improved the prognosis of patients with metastatic RCC (mRCC). Until then, treatment options were limited as these cancers are generally relatively resistant to cytotoxic chemotherapy [4]. Before 2005, interferon-alpha (IFN-alpha) and high-dose (HD) interleukin (IL)-2 cytokine-based therapies were standard therapy for metastatic RCC (mRCC). However, low response rates and a high 
incidence of adverse events made this option suitable only for a specific subset of patients $[10,11]$. The multitarget tyrosine kinase inhibitors (TKIs) sunitinib and sorafenib became the first new therapies approved for advanced RCC and have been available in Switzerland since 2006. Both drugs were approved based on prospective, randomized phase 3 trial showing improved progression free survival (PFS) compared to IFN-alpha or placebo, respectively[12,13]. Thereafter, other TKIs (axitinib, pazopanib) have been approved for first- or second-line therapy $[14,15]$ as well as the mTOR inhibitors everolimus and temsirolimus [16,17] and the combination of the monoclonal VEGF-antibody bevacizumab in combination with low-dose IFN-alpha [18].

Before the introduction of molecular-targeted drugs, radical nephrectomy has been the preferred treatment, especially in patients with good performance status, based on the results of randomized controlled trials [8,19]. Although the benefit of radical nephrectomy has not been prospectively proven in the TKI-era, there are data supporting this procedure [20] and it is usually considered standard of care in patients with good performance status [21]. Several groups, mostly in retrospective analyses or case series, have evaluated the role of metastasectomy[22-24] in mRCC. In guidelines, metastasectomy is considered an option for selected patients after multidisciplinary evaluation [21].

Despite recent advances in the therapy of $\mathrm{mRCC}$, there are still a number of treatment challenges, including the role of surgical procedures in the TKI-era and the most appropriate treatment sequences. Moreover, the implementation of novel treatment options and guidelines and their impact on population-based outcome has not been extensively studied so far. The aim of this retrospective analysis was to collect real-world demographic, treatment and outcome data from $\mathrm{mRCC}$ patients.

\section{Patients and Methods}

\section{Patients}

We identified 79 patients with metastatic RCC diagnosed at the University Hospital of Basel between January 2000 and December 2010 through a search in the patient's database of the Department of Medical Oncology at the University Hospital Basel. Information on baseline patient and tumor characteristics, treatments, response and toxicity were retrospectively collected from the hospitals' electronic database and from patients' medical records. The trial was approved by the Cantonal Ethics Committee
(EKNZ, Ethical Committee of Northwestern and Central Switzerland). The last follow-up data was collected on December 31, 2015. Patients treated as part of clinical research trials were also included.

\section{Staging, response and outcome evaluation}

Tumor stage at initial diagnosis was categorized according to the American Joint Committee on Cancer (AJCC) TNM classification of malignant tumors, $7^{\text {th }}$ edition, 2009. [3] Overall response rate (ORR) was defined according to Response Evaluation Criteria In Solid Tumors (RECIST) criteria version 1.0[25]. Progression-free survival (PFS) was defined as the time from start of therapy to disease progression or death, whichever occurred first. Overall survival (OS) was defined as time from time of diagnosis of metastatic disease to death by any cause. Standard values for Motzer/Heng criteria were defined as follows: hemoglobin in men $\geq 12.9 \mathrm{~g} / \mathrm{dl}$, hemoglobin in women $\geq 12.0 \mathrm{~g} / \mathrm{dl}, \mathrm{LDH} \leq 245 \mathrm{U} / \mathrm{I}$, neutrophiles $6.2 \times 10^{9} / 1^{*}$ and thrombocytes $\geq 450 \times 10^{6} / 1^{*}$ (*indicates Heng criteria only).

Some patient records did not include data for all parameters; available data from these patients were used where appropriate.

\section{Statistics}

Descriptive statistics were used to describe baseline characteristics and treatment patterns. PFS and OS were estimated using the Kaplan-Meier method. Comparisons of outcome parameters were calculated using the log-rank test and the Mann-Whitney test. We used a significance level of $\mathrm{p}<0.05$ for all tests. SPSS statistical software version 22 (IBM Corporation, New York, USA) was used for all analyses.

\section{Results}

\section{Patient characteristics}

We identified 79 patients with RCC diagnosed between January 2000 and December 2010 at our institution. Patient demographics and baseline characteristics are detailed in Table 1. In summary, mean age at initial diagnosis of metastatic disease was 60.8 years (range, 37.3-85.0 years). 62 patients (78.5\%) were male. 64 patients $(81 \%)$ were diagnosed with clear cell histology and 10 patients $(12.7 \%)$ had papillary histology, in 14 patients $(17.7 \%)$ a sarcomatoid differentiation was found. At initial diagnosis, 44 patients $(55.7 \%)$ had metastatic disease. For patients initially diagnosed with localized disease, median time to metastatic disease was 34.3 months. At the time of diagnosis of metastatic RCC, the lung was the most common site for metastases (59 patients, $74.7 \%$ ) followed by non-regional lymph nodes (43 
patients, $54.4 \%$ ), bone (24 patients, $30.4 \%$ ), liver (16 patients, $20.3 \%)$ and brain (7 patients, $8.9 \%)$. In the whole cohort, the median OS from diagnosis of metastatic disease was 24.4 months (95\% CI 16.7-32.2). Median OS from time of first diagnosis of RCC was 37.4 months (95\% CI 23.5-50.9). At the time of data cut off (31.12.2015), 64 patients were deceased and 2 patients were still alive. 13 patients were lost to follow-up and were therefore not included in outcome analysis. Both patients that are still alive were male harboring a clear-cell mRCC and were diagnosed and treated in the TKI-era. The first patient had histologically proven multiple lung metastases at diagnosis and was treated with sunitinib in the first-line setting. After 8 months and a radiographic near complete remission, treatment was interrupted due to toxicity. The patient did not have a relapse since October 2007. The second patient was initially diagnosed with pT2 tumor in 1998 and underwent nephrectomy. In 2006 four lung metastases and a solitary brain metastasis were resected. In 2009 a solitary adrenal gland metastasis was surgically removed by an adrenalectomy. Since then the patient is in complete remission.

\section{Prognostic scores}

61 patients were evaluable for analysis of Motzer score and 58 patients were evaluable for analysis of Heng Score. 8 (10.1\%) were classified as good risk, 39 patients $(49.4 \%)$ as intermediate and $14(17.7 \%)$ as poor risk. Median OS was 42.4, 18.7 and 9.4 months $(p=0.006)$ for patients with good, intermediate and poor risk classification according to Motzer Score (Figure 1A). 7 patients $(8.9 \%)$ had a good prognosis according to the Heng score, $33(41.8 \%)$ an intermediate and $18(22.8 \%)$ a poor prognosis. Median OS for these prognostic groups was 42.4, 17.6 and 13.3 months, respectively $(p=0.04)$ (Figure 1B). Mean values for each prognostic criterion used for Motzer and Heng Scores are summarized in Table 2.

Male patients showed a trend towards improved survival when compared to female patients (median OS 24.5 vs. 17.6 months, n.s.) Patients with a sarcomatoid component showed poorer outcome than patients without (median OS 11.1 vs. 24.5 months, n.s.). Brain metastases were associated with shorter survival (median OS 24.5 vs. 9.4 months, n.s.). Other metastatic sites showed no correlation to outcome.

\section{First-line therapy and outcome}

68 patients had a first-line systemic treatment. The other 11 patients either underwent a surgical procedure or a watch and wait strategy. 16 patients (23.5\%) received a TKI, 20 patients $(29.4 \%)$ were treated with an interferon-alpha, 5 patients $(7.4 \%)$ received chemotherapy (mostly gemcitabine), and 27 patients $(39.7 \%)$ were treated with an experimental therapy or within a clinical trial (mostly vaccination). 8 patients $(11.8 \%)$ had a tumor response, 23 patients $(33.9 \%)$ showed disease stabilization. In TKI treated patients these rates were $31.3 \%$ and $25 \%$, respectively. Median PFS for first-line therapy was 3.8 months in the whole cohort; 3.7 months in TKI treated patients. 22 patients $(27.8 \%)$ were treated with an additional radiotherapy.

Table 1. Patient demographics and baseline characteristics at time of initial diagnosis $(n=79)$.

\begin{tabular}{|c|c|c|}
\hline Characteristic $(\mathrm{n}=79)$ & Absolute & Relative \\
\hline $\begin{array}{l}\text { Median age at diagnosis, } \\
\text { years (range) }\end{array}$ & $61.7(37.3-79.8)$ & \\
\hline \multicolumn{3}{|l|}{ Gender } \\
\hline Male & 62 & $78.5 \%$ \\
\hline Female & 17 & $21.5 \%$ \\
\hline \multicolumn{3}{|c|}{ Extent of disease at study entry } \\
\hline Localized & 35 & $44.3 \%$ \\
\hline Metastatic & 44 & $55.7 \%$ \\
\hline \multicolumn{3}{|l|}{ Localization of metastases } \\
\hline Lung & 59 & $74.7 \%$ \\
\hline Liver & 16 & $20.3 \%$ \\
\hline Bone & 24 & $30.4 \%$ \\
\hline Brain & 7 & $8.9 \%$ \\
\hline \multicolumn{3}{|l|}{ Histological subtype } \\
\hline Clear cell & 67 & $84.8 \%$ \\
\hline Papillary & 10 & $12.7 \%$ \\
\hline Chromophobe & 1 & $1.3 \%$ \\
\hline Not specified & 1 & $1.3 \%$ \\
\hline \multicolumn{3}{|c|}{ Karnofsky Performance Status } \\
\hline $100 \%$ & 15 & $19.0 \%$ \\
\hline $90 \%$ & 47 & $59.5 \%$ \\
\hline $80 \%$ & 4 & $5.1 \%$ \\
\hline$<80 \%$ & 2 & $2.6 \%$ \\
\hline missing & 11 & $13.9 \%$ \\
\hline \multicolumn{3}{|l|}{ Smoking Status } \\
\hline Current smoker & 24 & $30.4 \%$ \\
\hline Former smoker & 23 & $29.1 \%$ \\
\hline Never smoker & 18 & $22.8 \%$ \\
\hline Unknown & 14 & $17.7 \%$ \\
\hline \multicolumn{3}{|l|}{ Motzer Score } \\
\hline Favorable & 8 & $10.1 \%$ \\
\hline Intermediate & 39 & $49.4 \%$ \\
\hline Poor & 14 & $17.7 \%$ \\
\hline Missing & 18 & $22.8 \%$ \\
\hline \multicolumn{3}{|l|}{ Heng Score } \\
\hline Favorable & 7 & $8.9 \%$ \\
\hline Intermediate & 33 & $41.8 \%$ \\
\hline Poor & 18 & $22.8 \%$ \\
\hline Missing & 21 & $26.6 \%$ \\
\hline
\end{tabular}

Table 2. Laboratory values for calculation of Motzer and Heng Score.

\begin{tabular}{lll}
\hline Laboratory value & Mean & Minimum, Maximum \\
\hline Hemoglobin $(\mathrm{n}=63)$ & $12.8 \mathrm{~g} / \mathrm{l}$ & $9.4-17.5$ \\
Thrombocytes $(\mathrm{n}=62)$ & $317.6 \mathrm{G} / 1$ & $60-751$ \\
Neutrophiles $(\mathrm{n}=47)$ & $6.2 \mathrm{G} / 1$ & $2.7-16.9$ \\
Calcium $(\mathrm{n}=59)$ & 2.3 & $1.6-2.9$ \\
Albumin $(\mathrm{n}=57)$ & 36.3 & $14-73$ \\
LDH $(\mathrm{n}=51)$ & $260 \mathrm{IU} / 1$ & $69-3^{\prime} 463$ \\
\hline
\end{tabular}



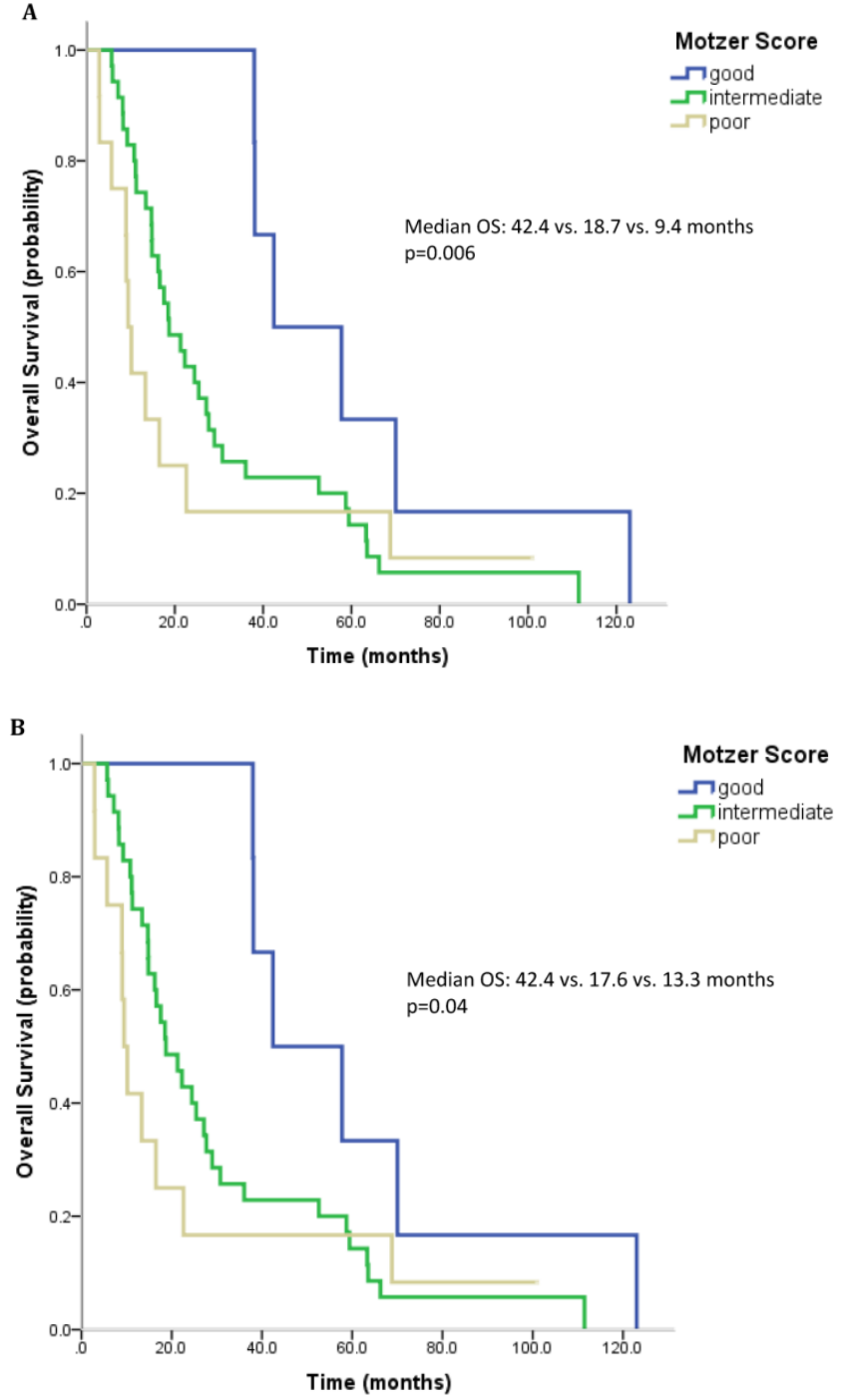

Figure 1. Outcome parameters according to prognostic scores. Kaplan-Meier plots for overall survival in relation to Motzer Score (A) and Heng Score (B).

\section{Second-line therapy and outcome}

45 received a systemic treatment. 16 patients (35.6\%) were treated with a TKI, 4 patients $(8.9 \%)$ with a mTOR inhibitor and 7 patients $(15.6 \%)$ with interferon-alpha. 5 patients $(11.1 \%)$ were treated with gemcitabine and 13 patients $(32.5 \%)$ received an experimental therapy or were treated within a clinical study. 7 patients $(15.6 \%)$ showed a radiographic response to the second-line therapy, 10 patients (22.2\%) achieved disease stabilization. For patients treated with a TKI or an mTOR inhibitor these rates were $25 \%$ and $30 \%$, respectively. Median PFS for second-line therapy was 2.4 months in the whole cohort and 3.8 months for patients treated with a TKI or an mTOR inhibitor. 12 patients $(15.2 \%)$ were additionally treated with irradiation.

\section{Third- and later line therapy and outcome}

23 patients $(29.1 \%)$ were treated with more than Characteristics of third and later line therapies are summarized in Table 3 . Overall response rates in third-, fourth- and fifth-line therapy were $34.8 \%$, $15.4 \%$, and $0 \%$.

Table 3. Overview on treatment details beyond second-line therapy.

\begin{tabular}{llllll}
\hline Treatment line & TKI & mTOR & $\begin{array}{l}\text { Immuno- } \\
\text { therapy }\end{array}$ & $\begin{array}{l}\text { Chemo- } \\
\text { therapy }\end{array}$ & $\begin{array}{l}\text { Experimental } \\
\text { therapy / } \\
\text { clinical trial }\end{array}$ \\
\hline 3rd-line $(\mathrm{n}=23)$ & $9(39.1 \%)$ & $2(8.7 \%)$ & $6(26.1 \%)$ & $3(13 \%)$ & $3(13 \%)$ \\
4th-line $(\mathrm{n}=13)$ & $7(53.8 \%)$ & $2(15.4 \%)$ & $1(7.7 \%)$ & $1(7.7 \%)$ & $2(15.4 \%)$ \\
5th-line $(\mathrm{n}=2)$ & $1(\mathrm{n}=50 \%)$ & 0 & 0 & 0 & $1(\mathrm{n}=50 \%)$ \\
\hline
\end{tabular}

Immunotherapy: Interferon-alpha, Interferon-alpha + Bevacizumab, Interleukin-2.

\section{Treatment with modern agents}

17 patients $(21.5 \%)$ were diagnosed after 2006 (TKI-era). 32 patients $(40.5 \%)$ received at least one TKI in the course of mRCC. 7 patients $(8.9 \%)$ were treated with a mTOR inhibitor. In summary, 32 patients $(40.5 \%)$ received at least one modern and approved anticancer therapy (TKI and/or mTOR inhibitor). Patients treated with at least on TKI had a median OS of 25.4 months (95\%CI 13.6-37.2), whereas patients that have not received a TKI had a median OS of 22.6 months (95\%CI 10.3-34.9) $(\mathrm{p}=0.167)$ (Figure 2A). All patients treated with an mTOR inhibitor have also received a TKI. These patients had a significantly better outcome than patients that were not exposed to an mTOR inhibitor (median OS 63.3 vs. 22.3 months, $\mathrm{p}=0.038$ ). Patients treated with at least two lines of therapy had a significantly longer OS (Median OS: 43.8 vs. 17.6 months, $p=0.002$ ) (Figure 2B). The number of treatment lines was associated with OS in multivariate analysis $(\mathrm{p}=0.05)$.

\section{Surgical therapy}

Most patients underwent a nephrectomy (75 patients, 94.9\%). Patients without nephrectomy had a poorer survival than patients with nephrectomy (median OS 9.0 vs. 24.4 months, n.s.). 38 patients $(57.6 \%)$ underwent surgical metastasectomy. Metastasectomy significantly improved the outcome (median OS 29.0 vs. 16.2 months, p=0.007) (Figure 3). When comparing the effect of metastasectomy in patients treated with modern therapies (TKIs and/or mTOR inhibitors) with patients not having received any of the novel therapeutics, metastasectomy prolonged survival in both subgroups. However, only in patients not having received novel therapeutics this difference reached statistical significance (Median OS: 29.0 vs. 13.3 months, $p=0.047$ and 27.1 vs. 17.6 months, $\mathrm{p}=0.162)$. 


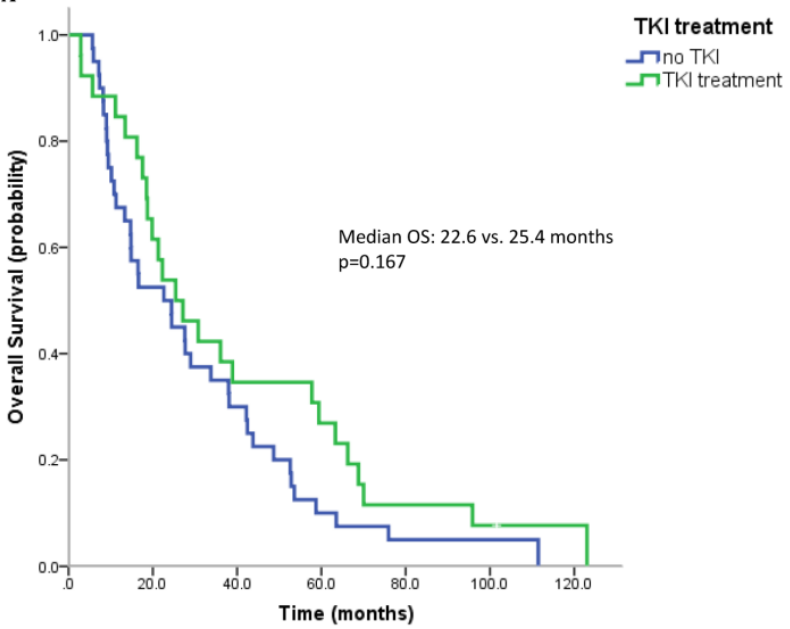

B

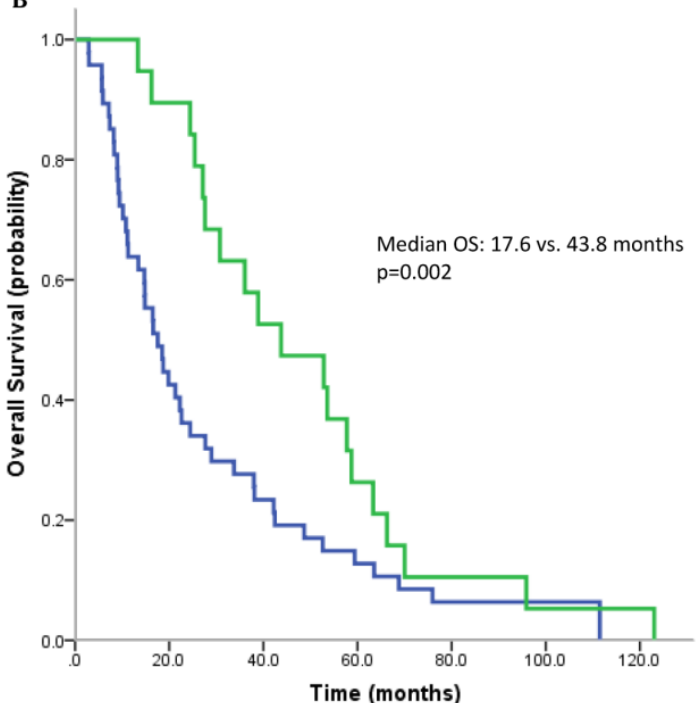

Figure 2. A. Overall survival for patients treated with and without a TKI. B. Overall survival for patients with more than two treatment lines or less.

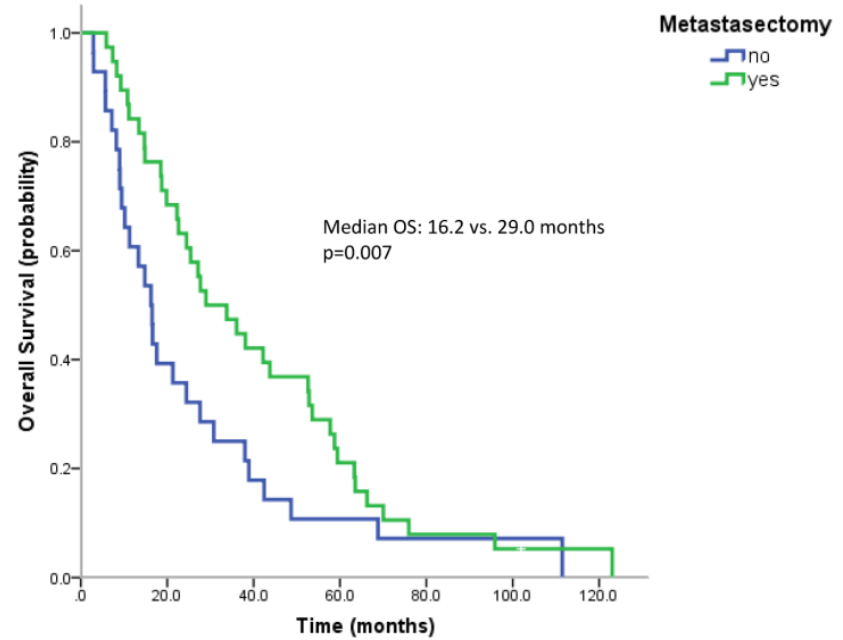

Figure 3. Kaplan Meier curves for patients undergoing metastasectomy or not.

\section{Discussion}

This retrospective analysis including all patients with the diagnosis of mRCC treated at our department between 2000 and 2010 provides information on "real-world" treatment patterns and outcomes of mRCC patients from a large University Hospital in Switzerland. Median OS of the whole RCC population in our study, as estimated by Kaplan-Meier method, was 37.4 months. Compared to larger RCC registries, this rate is clearly inferior reflecting the high rate of patients presenting with metastatic disease at diagnosis $(55.7 \%)$. In a recently published analysis from a Swedish registry this rate was $27 \%$ and the median OS 60.5 months [26]. The median OS for the whole cohort from the diagnosis of mRCC was 24.4 months comparable to other published series on treated patients with cytokines and TKIs $[10,27,28]$. The majority of patients (62 patients, $78.5 \%$ ) in our analysis were diagnosed before the approval of the first TKI in 2006. The median OS for patients diagnosed after 2006 was not different, as many of the patients diagnosed in earlier years also received novel therapies (18/62 patients, 29\%). However, by comparing outcomes of patients having received at least one TKI during their treatment course, we found a trend towards better survival for patients having received at least one TKI (median OS 25.4 vs. 22.6 months, n.s.). Some of the patients also received their first TKI in a very late stage of their disease after having received unapproved or experimental drugs at the time TKIs have not been available. Thus, we separately analyzed patients having received a TKI as first- or second-line therapy and could show a significant survival benefit compared to patients who did not receive a TKI (median OS 27.1 vs. 22.6 months, $\mathrm{p}=0.03$ ). In summary, outcome results from our retrospective analysis are somewhat inferior to the results from a recent clinical trial comparing the two TKIs pazopanib (28.4 months) and sunitinib (29.3 months)[14]. However, in our retrospective analysis, $17.3 \%$ and $22.2 \%$ of patients were classified in a poor prognostic group according to Motzer [29,30] and Heng Criteria[31], respectively. These patients are usually not included in clinical trials and have a poor outcome. A large retrospective analysis from 2210 US patients has shown that patients that would be ineligible for clinical trials do not benefit to the same extent from TKI as those who would be. OS of the latter was only 12.5 months compared to 28.4 months of the fit for trial patients [32].

We could confirm the prognostic value of both scores by showing significantly different survival rates. 
In a recently published pattern of care study from UK including patients treated between 2004 and 2011 , only $15.8 \%$ of patients received second-line therapy reflecting the limited access to novel therapies in the UK [33]. Although our analysis includes more patients treated in the pre-TKI era (before 2006), the rate of Swiss patients who received a systemic second-line therapy was $57 \%$. When considering approved TKIs or mTOR inhibitors, $44.5 \%$ of patients in our analysis received second-line therapy. The rate of patients with third-, fourth-, and fifth-line therapy was $29.1 \%, 16.5 \%$, and $2.5 \%$. One of the most important factors for prognosis in our analysis is the number of therapies. Patients who receive a second-line therapy have a nearly doubled median OS ( 27.6 vs. 14.8 months, $p=0.06$ ). This effect was even more pronounced in patients treated with three or more lines of systemic therapy (median OS 43.8 vs. 17.6 months, $\mathrm{p}=0.002$ ). This may be due to selection bias as patients with a good prognosis are more likely to receive further lines of therapy or because treatment options beyond first-line therapy can really improve survival. The prognostic effect of a second-line therapy was also shown in the RECCORD registry from UK where only a minority of patients received a second-line therapy [33].

In further analyses we investigated the influence of surgical procedures. As expected, previous nephrectomy, the standard of care for patients with localized disease, was associated with better outcome. The impact of cytoreductive nephrectomy is well established in in patients with mRCC treated with IFN $[8,19]$ and seems also to improve survival rates with targeted therapies [20,34], mainly in patients in a better prognostic group. In our analysis, the impact of nephrectomy was more pronounced in the overall RCC population than in mRCC patients, probably reflecting the curative option of nephrectomy in patients with localized RCC.

Surgical resection of RCC metastases is a possible treatment option when considering accessibility and resectability of metastatic lesions as well as patients' performance status and comorbidities [35]. The role of metastasectomy has never been analyzed in randomized manner and there are also no prospective non-randomized comparative studies. A recent systematic review included 16 retrospective comparative studies analyzing local treatment options (surgery or radiotherapy) of metastases from RCC in various organs [36]. As there was a great heterogeneity of data a formal meta-analysis was not possible. The majority of trials showed a significantly longer median OS or cancer-specific survival after complete metastasectomy compared with incomplete or no metastasectomy. Moreover, there seems to be a benefit in regard to symptom control. In our cohort, we found a significantly improved overall survival for patients undergoing metastasectomy. This effect was less pronounced in patients treated with modern therapies (TKIs and/or mTOR inhibitors). However, these results have to be interpreted cautiously as a bias in patient selection cannot be excluded in a retrospective analysis. Recent trials could also show a benefit of metastasectomy in patients treated with TKIs [37][23,24]. For the resection of lung metastases, a new prognostic score (Munich score) has been suggested to predict long-term survival [38]. Due to lack of data we were not able to validate this score in our cohort. However, beside differences regarding systemic therapies, we could not find another clinical factor influencing the highly statistically significant survival benefit of metastasectomy in our patients.

In the present study, we attempted to characterize treatments, outcome and prognostic factors during a ten-year period at a University Hospital in Switzerland. Despite the unselected patient cohort reflecting "real-world" mRCC patients, the overall outcome was comparable to outcome data from large prospective clinical trials including selected patients. We could confirm an improved prognosis for patients treated with targeted therapies, mainly TKIs and mTOR inhibitors. A high proportion of patients were treated with more than two systemic therapies reflecting the high quality of the health care system in our country with availability and reimbursement of various treatment lines for mRCC patients. Furthermore, many patients in this study benefitted from metastasectomy what additionally improved their outcome. Although its efficiency has never been prospectively validated, metastasectomy should be carefully considered in mRCC patients and these patients need to be individually evaluated by a multidisciplinary team, as it is standard at our center. With the approval of novel treatment options (e.g. immune checkpoint inhibitors) treatment decisions will be even more challenging in the near future.

\section{Conflicts of Interest}

The author declares that the research was conducted in the absence of any commercial or financial relationships that could be construed as a potential conflict of interest.

\section{References}

1. Ljungberg B, Campbell SC, Choi HY, Cho HY, Jacqmin D, Lee JE, et al. The epidemiology of renal cell carcinoma. Eur Urol 2011 Oct;60:615-21.

2. Ljungberg B, Bensalah K, Canfield S, Dabestani S, Hofmann F, Hora M, et al. EAU Guidelines on Renal Cell Carcinoma: 2014 Update. Eur Urol 2015;:1-12.

3. Escudier B, Eisen T, Porta C, Patard JJ, Khoo V, Algaba F, et al. Renal cell carcinoma: ESMO clinical practice guidelines for diagnosis, treatment and follow-up. Ann Oncol 2012;23. DOI: 10.1093/annonc/mds227 
4. Abe $\mathrm{H}$, Kamai $\mathrm{T}$ : Recent advances in the treatment of metastatic renal cell carcinoma. Int J Urol 2013 Oct;20:944-55.

5. Winter H, Meimarakis G, Angele MK, Hummel M, Staehler M, Hoffmann R-T, et al. Tumor infiltrated hilar and mediastinal lymph nodes are an independent prognostic factor for decreased survival after pulmonary metastasectomy in patients with renal cell carcinoma. J Urol 2010 Nov;184:1888-94.

6. Piltz S, Meimarakis G, Wichmann MW, Hatz R, Schildberg FW, Fuerst H: Long-term results after pulmonary resection of renal cell carcinoma metastases. Ann Thorac Surg 2002 Apr;73:1082-7.

7. Murthy SC, Kim K, Rice TW, Rajeswaran J, Bukowski R, DeCamp MM, et al. Can we predict long-term survival after pulmonary metastasectomy for renal cell carcinoma? Ann Thorac Surg 2005 Mar;79:996-1003.

8. Mickisch GH, Garin A, van Poppel H, de Prijck L, Sylvester R: Radical nephrectomy plus interferon-alfa-based immunotherapy compared with interferon alfa alone in metastatic renal-cell carcinoma: a randomised trial. Lancet (London, England) 2001 Sep 22;358:966-70.

9. Cohen HT, McGovern FJ: Renal-cell carcinoma. N Engl J Med 2005 Dec 8;353:2477-90.

10. Coppin C, Porzsolt F, Awa A, Kumpf J, Coldman A, Wilt T: Immunotherapy for advanced renal cell cancer. Cochrane database Syst Rev 2005 Jan;CD001425.

11. Bukowski RM: Cytokine therapy for metastatic renal cell carcinoma. Semin Urol Oncol 2001 May;19:148-54.

12. Motzer RJ, Hutson TE, Tomczak P, Michaelson MD, Bukowski RM, Rixe O, et al. Sunitinib versus interferon alfa in metastatic renal-cell carcinoma. N Engl J Med 2007;356:115-124

13. Escudier B, Eisen T, Stadler WM, Szczylik C, Oudard S, Siebels M, et al. Sorafenib in advanced clear-cell renal-cell carcinoma. N Engl J Med 2007 Jan 11;356:125-134.

14. Motzer RJ, Hutson TE, Cella D, Reeves J, Hawkins R, Guo J, et al. Pazopanib versus sunitinib in metastatic renal-cell carcinoma. N Engl J Med 2013 Aug 22;369:722-31.

15. Rini BI, Escudier B, Tomczak P, Kaprin A, Szczylik C, Hutson TE, et al. Comparative effectiveness of axitinib versus sorafenib in advanced renal cell carcinoma (AXIS): a randomised phase 3 trial. Lancet 2011 Dec 3;378:1931-1939

16. Motzer RJ, Escudier B, Oudard S, Hutson TE, Porta C, Bracarda S, et al. Efficacy of everolimus in advanced renal cell carcinoma: a double-blind, randomised, placebo-controlled phase III trial. Lancet 2008;372:449-456.

17. Hudes G, Carducci M, Tomczak P, Dutcher J, Figlin R, Kapoor A, et al. Temsirolimus, interferon alfa, or both for advanced renal-cell carcinoma. $\mathrm{N}$ Engl J Med 2007;356:2271-2281.

18. Rini BI, Halabi S, Rosenberg JE, Stadler WM, Vaena DA, Archer L, et al. Phase III trial of bevacizumab plus interferon alfa versus interferon alfa monotherapy in patients with metastatic renal cell carcinoma: final results of CALGB 90206. J Clin Oncol 2010 May 1;28:2137-43.

19. Flanigan RC, Salmon SE, Blumenstein BA, Bearman SI, Roy V, McGrath PC, et al. Nephrectomy followed by interferon alfa- $2 b$ compared with interferon alfa-2b alone for metastatic renal-cell cancer. N Engl J Med 2001 Dec 6;345:1655-9.

20. Heng DYC, Wells JC, Rini BI, Beuselinck B, Lee J-L, Knox JJ, et al. Cytoreductive Nephrectomy in Patients with Synchronous Metastases from Renal Cell Carcinoma: Results from the International Metastatic Renal Cell Carcinoma Database Consortium. Eur Urol 2014 Oct;66:704-710.

21. Escudier B, Porta C, Schmidinger M, Algaba F, Patard JJ, Khoo V, et al. Renal cell carcinoma: ESMO Clinical Practice Guidelines for diagnosis, treatment and follow-up. Ann Oncol 2014 Sep;25 Suppl 3:iii49-56.

22. Johannsen M, Staehler M, Ohlmann C-H, Flörcken A, Schmittel A, Otto T, et al. Outcome of treatment discontinuation in patients with metastatic renal cell carcinoma and no evidence of disease following targeted therapy with or without metastasectomy. Ann Oncol 2011 Mar;22:657-63.

23. Tosco L, Van Poppel H, Frea B, Gregoraci G, Joniau S: Survival and impact of clinical prognostic factors in surgically treated metastatic renal cell carcinoma. Eur Urol 2013 Apr;63:646-52.

24. Naito $\mathrm{S}$, Kinoshita $\mathrm{H}$, Kondo $\mathrm{T}$, Shinohara $\mathrm{N}$, Kasahara $\mathrm{T}$, Saito $\mathrm{K}$, et al. Prognostic factors of patients with metastatic renal cell carcinoma with removed metastases: a multicenter study of 556 patients. Urology 2013 Oct; $82: 846-51$

25. Therasse P, Arbuck SG, Eisenhauer EA, Wanders J, Kaplan RS, Rubinstein L, et al. New guidelines to evaluate the response to treatment in solid tumors. European Organization for Research and Treatment of Cancer, National Cancer Institute of the United States, National Cancer Institute of Canada. J Natl Cancer Inst 2000 Feb 2;92:205-16.

26. Wahlgren T, Harmenberg U, Sandström P, Lundstam S, Kowalski J, Jakobsson $\mathrm{M}$, et al. Treatment and overall survival in renal cell carcinoma: a Swedish population-based study (2000-2008). Br J Cancer 2013 Apr 16;108:1541-9.

27. Gore ME, Szczylik C, Porta C, Bracarda S, Bjarnason GA, Oudard S, et al. Safety and efficacy of sunitinib for metastatic renal-cell carcinoma: an expanded-access trial. Lancet Oncol 2009 Aug:10:757-63.

28. Stadler WM, Figlin RA, McDermott DF, Dutcher JP, Knox JJ, Miller WH, et al. Safety and efficacy results of the advanced renal cell carcinoma sorafenib expanded access program in North America. Cancer 2010 Mar 1;116:1272-80.

29. Motzer RJ, Mazumdar M, Bacik J, Berg W, Amsterdam A, Ferrara J: Survival and prognostic stratification of 670 patients with advanced renal cell carcinoma. J Clin Oncol 1999;17:2530-2540.
30. Motzer RJ, Bacik J, Mariani T, Russo P, Mazumdar M, Reuter V: Treatment outcome and survival associated with metastatic renal cell carcinoma of non-clear-cell histology. J Clin Oncol 2002;20:2376-2381.

31. Heng DY, Xie W, Regan MM, Warren MA, Golshayan AR, Sahi C, et al. Prognostic factors for overall survival in patients with metastatic renal cell carcinoma treated with vascular endothelial growth factor-targeted agents: results from a large, multicenter study. J Clin Oncol 2009;27:5794-5799.

32. Heng DYC, Choueiri TK, Rini BI, Lee J, Yuasa T, Pal SK, et al. Outcomes of patients with metastatic renal cell carcinoma that do not meet eligibility riteria for clinical trials. Ann Oncol 2014 Jan;25:149-54.

33. Wagstaff J, Jones R, Hawkins R, Porfiri E, Pickering L, Bahl A, et al. Treatment patterns and clinical outcomes in patients with renal cell carcinoma in the UK: insights from the RECCORD registry. Ann Oncol 2016 Jan;27:159-65.

34. Choueiri TK, Xie W, Kollmannsberger C, North S, Knox JJ, Lampard JG, et al. The impact of cytoreductive nephrectomy on survival of patients with metastatic renal cell carcinoma receiving vascular endothelial growth factor targeted therapy. J Urol 2011 Jan;185:60-6.

35. Alt AL, Boorjian SA, Lohse CM, Costello BA, Leibovich BC, Blute ML: Survival after complete surgical resection of multiple metastases from renal cell carcinoma. Cancer 2011 Jul 1;117:2873-82.

36. Dabestani S, Marconi L, Hofmann F, Stewart F, Lam TBL, Canfield SE, et al. Local treatments for metastases of renal cell carcinoma: a systematic review. Lancet Oncol 2014 Nov;15:e549-61.

37. Yu X, Wang B, Li X, Lin G, Zhang C, Yang Y, et al. The Significance of Metastasectomy in Patients with Metastatic Renal Cell Carcinoma in the Era of Targeted Therapy. Biomed Res Int 2015 Jan;2015:176373.

38. Meimarakis G, Angele M, Staehler M, Clevert D-A, Crispin A, Rüttinger D, et al. Evaluation of a new prognostic score (Munich score) to predict long-term survival after resection of pulmonary renal cell carcinoma metastases. Am J Surg 2011 Aug;202:158-67. 